Supplement of Biogeosciences, 14, 921-939, 2017

http://www.biogeosciences.net/14/921/2017/

doi:10.5194/bg-14-921-2017-supplement

(C) Author(s) 2017. CC Attribution 3.0 License.

(c) (i)

Supplement of

\title{
Multi-frequency electrical impedance tomography as a non-invasive tool to characterize and monitor crop root systems
}

Maximilian Weigand and Andreas Kemna

Correspondence to: Maximilian Weigand (mweigand@geo.uni-bonn.de)

The copyright of individual parts of the supplement might differ from the CC-BY 3.0 licence. 

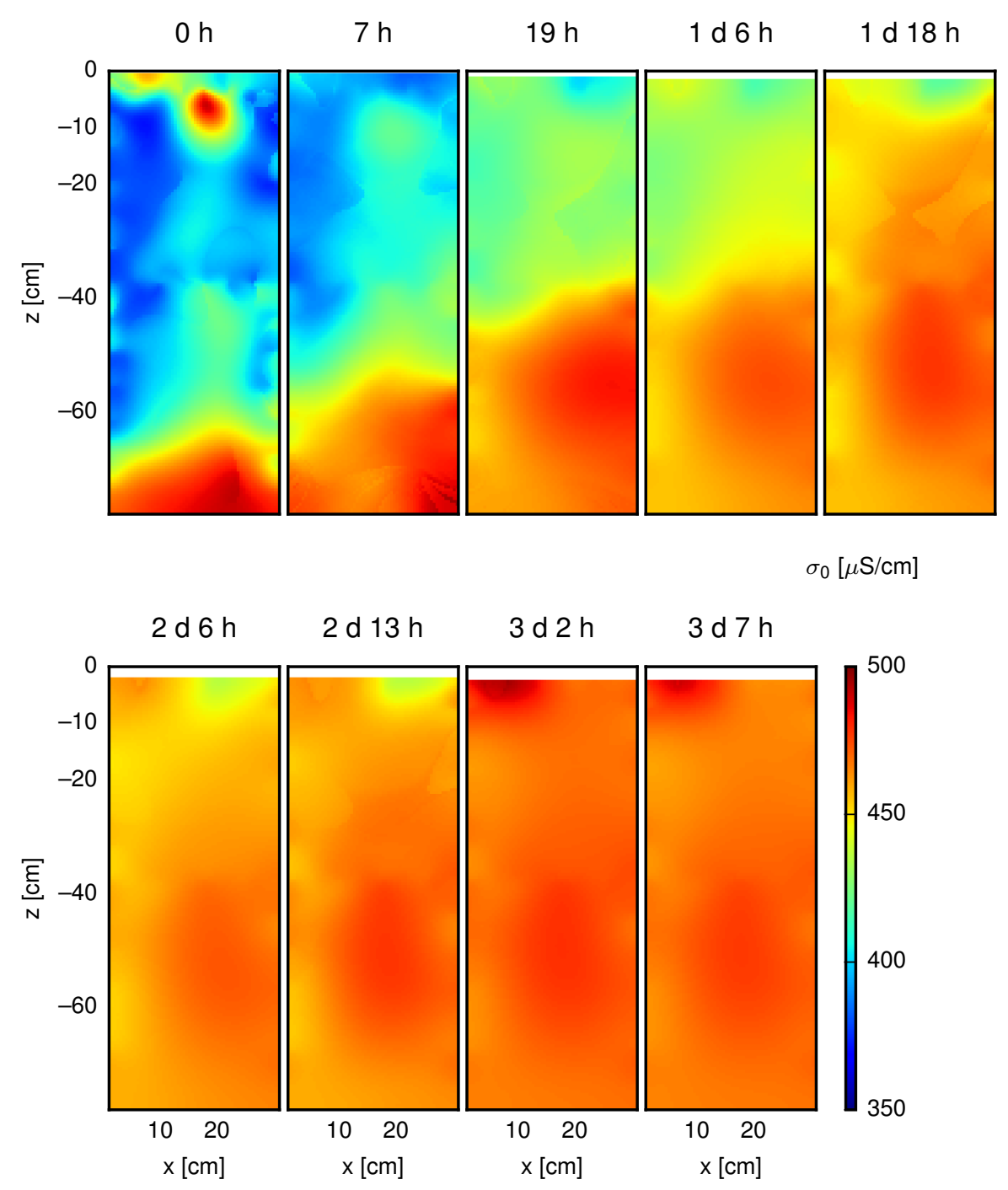

Supplement 1: Spatial distribution of the DD-derived parameter $\sigma_{0}$ for selected time steps. The top boundary is adjusted according to the estimated water table for each measurement time. 